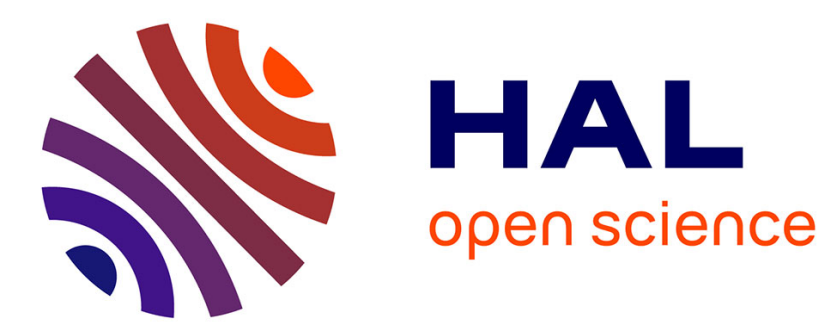

\title{
The effect of a multivalley energy band structure on the thermoelectric figure of merit
}

D.M. Rowe, C.M. Bhandari

\section{To cite this version:}

D.M. Rowe, C.M. Bhandari. The effect of a multivalley energy band structure on the thermoelectric figure of merit. Journal de Physique Lettres, 1985, 46 (1), pp.49-52. 10.1051/jphyslet:0198500460104900 . jpa-00232475

\section{HAL Id: jpa-00232475 https://hal.science/jpa-00232475}

Submitted on 1 Jan 1985

HAL is a multi-disciplinary open access archive for the deposit and dissemination of scientific research documents, whether they are published or not. The documents may come from teaching and research institutions in France or abroad, or from public or private research centers.
L'archive ouverte pluridisciplinaire HAL, est destinée au dépôt et à la diffusion de documents scientifiques de niveau recherche, publiés ou non, émanant des établissements d'enseignement et de recherche français ou étrangers, des laboratoires publics ou privés. 
Classification

Physics Abstracts

$72.20 \mathrm{P}$

\title{
The effect of a multivalley energy band structure on the thermoelectric figure of merit
}

\author{
D. M. Rowe and C. M. Bhandari \\ Dept. of Physics, Electronics and Electrical Engineering, U.W.I.S.T., P.O. Box 25, \\ King Edward VII avenue, Cathays Park, Cardiff CF1 3XE, U.K.
}

(Reçu le 5 octobre 1984, accepté le 16 novembre 1984)

\begin{abstract}
Résumé. - Les coefficients de qualité thermoélectrique sans dimension de semiconducteurs à vallées multiples $(Z T)_{\mathrm{mv}}$ ou à vallée unique $(Z T)_{\mathrm{sv}}$ sont ici comparés. La diffusion des phonons acoustiques et celle des impuretés ionisées sont prises en considération. Bien qu'il soit avantageux pour les applications thermoélectriques d'utiliser un semiconducteur à vallées multiples, l'effet bénéfique est réduit par l'augmentation de la concentration des porteurs et la présence de diffusion inter-vallées. Lorsque la concentration des porteurs est optimale pour le coefficient de qualité thermoélectrique, le coefficient $(Z T)_{\mathrm{mv}} /(Z T)_{\mathrm{sv}}$ pour l'alliage silicium-germanium est réduit d'environ $40 \%$.
\end{abstract}

\begin{abstract}
A comparison is drawn between the dimensionless thermoelectric figure of merit of a multivalleyed semiconductor $(Z T)_{\mathrm{mv}}$ and one having a single valleyed structure $(Z T)_{\mathrm{sv}}$. In the analysis both acoustic phonon scattering and ionized impurity scattering are considered. Although it is advantageous to employ a multivalleyed semiconductor in thermoelectric applications it is concluded that the beneficial effect of a multivalleyed structure is reduced with increase in carrier concentration and the presence of intervalley scattering. At a carrier concentration which optimizes the thermoelectric figure of merit, the ratio $(Z T)_{\mathrm{mv}} /(Z T)_{\mathrm{sv}}$ for silicon-germanium alloy is reduced by approximately 40 percent.
\end{abstract}

It has been generally accepted for some considerable time that a semiconductor which possesses a multivalley energy band structure should exhibit a higher value of the thermoelectric figure of merit $Z$ than a similar material which has only a single valley. A comparison of the measured $Z$ values for thermoelectric semiconductors supports this view. Multivalleyed semiconductors such as bismuth telluride, lead telluride and silicon-germanium alloys are the best materials over their temperature ranges of operation [1]. Previous analyses have shown that in the non-degenerate limit and neglecting intervalley scattering of the charge carriers, the figure of merit increases monotonically with the number of valleys $N_{\mathrm{v}}[2,3]$. In practice thermoelectric semiconductors are doped to relatively high carrier concentrations in order to optimize the materials thermoelectric properties. In the region of optimum doping, a multivalley energy band structure and the intervalley scattering may have a significant effect on the figure of merit compared to that in the non-degenerate limit.

In this note we report the results of our calculations into the effect of intervalley scattering on the figure of merit of a multivalleyed semiconductor, as a function of carrier concentration $n$ 
(expressed in terms of reduced Fermi energy $\xi$ ). Assuming conduction in a single band semiconductor (electron or hole) the dimensionless figure of merit for a multivalleyed semiconductor $(Z T)_{\mathrm{mv}}$ (with $N_{\mathrm{v}}$ equivalent valleys) can be expressed as $[1,4]$

where

$$
(Z T)_{\mathrm{mv}}=\frac{\left(\alpha_{\mathrm{e}}^{\prime}\right)^{2}\left(\sigma_{\mathrm{e}}^{\prime}\right)_{\mathrm{mv}}}{1+\left(\sigma_{\mathrm{e}}^{\prime} \complement_{\mathrm{e}}\right)_{\mathrm{mv}}}
$$

The reduced electrical conductivity $\sigma_{\mathrm{e}}^{\prime}$ is given by

where

$$
\begin{gathered}
\sigma_{\mathrm{e}}^{\prime}=\beta \frac{F_{s+1 / 2}(\xi)}{(s+1 / 2) !} \\
\beta=\frac{2\left(2 \pi k_{\mathrm{B}}\right)^{3 / 2} k_{\mathrm{B}}^{2} A^{\prime}}{e h^{3}} \\
A^{\prime}=T^{5 / 2} m^{* 3 / 2} \mu / \lambda_{\mathrm{L}}
\end{gathered}
$$

The various symbols have the same meaning as in reference [1].

Assuming that the reduced Seebeck coefficient $\alpha_{e}^{\prime}$ is independent of the number of valleys and that the effect of intervalley scattering manifests itself primarily through the carrier mobility and electrical conductivity, the effect of a multivalley energy band structure on $Z T$ can conveniently be discussed in terms of the ratio [5]

$$
\frac{(Z T)_{\mathrm{mv}}}{(Z T)_{\mathrm{sv}}}=\frac{\left(\sigma_{\mathrm{e}}^{\prime}\right)_{\mathrm{mv}}\left\{1+\left(\sigma_{\mathrm{e}}^{\prime} \mathcal{L}_{\mathrm{e}}\right)_{\mathrm{sv}}\right\}}{\left(\sigma_{\mathrm{e}}^{\prime}\right)_{\mathrm{sv}}\left\{1+\left(\sigma_{\mathrm{e}}^{\prime} \mathcal{L}_{\mathrm{e}}\right)_{\mathrm{mv}}\right\}}
$$

In the non-degenerate limit, $-\xi \gg 1$ and in the absence of intervalley scattering

$$
\frac{(Z T)_{\mathrm{mv}}}{(Z T)_{\mathrm{sv}}}=N_{\mathrm{v}}
$$

The ratio $(Z T)_{\text {mv }} /(Z T)_{\text {sv }}$ can be evaluated as a function of the reduced Fermi energy or the carrier concentration, with $\xi$ and $n$ related by :

$$
n=4 \pi\left(\frac{2 k_{\mathrm{B}}}{\hbar^{2}}\right)^{3 / 2} N_{\mathrm{v}} m_{\mathrm{d}}^{* 3 / 2} T^{3 / 2} F_{1 / 2}(\xi)
$$

Here $m_{d}^{*}$ corresponds to the effective mass for a single valley i.e. $\left(m_{1}^{*} m_{2}^{*} m_{3}^{*}\right)^{1 / 3}$ where $m_{1}, m_{2}$ and $m_{3}$ refer to the components of the effective mass tensor along the principal directions.

The model formulated is a general one and equation (3) can be solved by numerical integration for different scattering mechanisms. Silicon-germanium alloys are of particular interest to us and the various parameters employed in the calculations are appropriate to $\mathrm{Si}_{70} \mathrm{Ge}_{30}$. The important carrier scattering mechanisms operating in these alloys at room temperature are acoustic phonon scattering and ionized impurity scattering with associated scattering parameters $s=-1 / 2$ and $3 / 2$ respectively. 
The material parameters $A^{\prime}$ are given by :

$$
A_{\text {acoustic }}^{\prime}=\frac{(8 \pi)^{1 / 2} e \hbar^{4}}{3 k^{3 / 2}} \frac{C_{11} T}{\varepsilon_{1}^{2} \lambda_{\mathrm{L}}} \frac{N_{\mathrm{v}}}{m_{\mathrm{c}}^{*}}
$$

and

$$
A_{\text {impurity }}^{\prime}=\frac{2^{7 / 2} k^{3 / 2} \chi^{2} m_{\mathrm{d}}^{* 2} T^{4}\left(N_{\mathrm{v}} / m_{\mathrm{c}}^{*}\right)}{\pi^{3 / 2} e^{3} N_{\mathrm{I}} \lambda_{\mathrm{L}} \ln \left[1+\left(\frac{3 \chi k T}{e^{2} N_{\mathrm{I}}^{1 / 3}}\right)^{2}\right]}
$$

Where $\varepsilon_{1}$ is the acoustic deformation potential, $C_{11}$ is the longitudinal elastic constant, $\chi$ is the dielectric constant and $N_{\mathrm{I}}$ is the concentration of ionized impurities (when each of the ionized impurities contribute one free electron, $N_{\mathrm{I}}=n$ ).

\section{Results.}

The ratio $(Z T)_{\mathrm{mv}} /(Z T)_{\mathrm{sv}}$ for $\mathrm{Si}_{70} \mathrm{Ge}_{30}$ alloy at $300 \mathrm{~K}$ is displayed in figure 1 as a function of carrier concentration. Both acoustic phonon scattering and ionized impurity scattering are considered, but without the inclusion of intervalley scattering. Both mechanisms lead to a value of $N_{\mathrm{v}}=6$ in the non-degenerate limit and this value decreases with an increase in carrier concentration. The pattern of the decrease in the ratio $(Z T)_{\mathrm{mv}} /(Z T)_{\mathrm{sv}}$ with carrier concentration is different for each mechanism. In the acoustic scattering case the decrease in this ratio occurs over the range of carrier concentration from $10^{24}$ to $10^{26} \mathrm{~m}^{-3}$, while for ionized impurity scattering the ratio remains almost constant at $N_{\mathrm{v}}=6$ up to a carrier concentration of $10^{25} \mathrm{~m}^{-3}$ and then decreases rapidly with increase in carrier concentration.

The exclusion of intervalley scattering may not be justified, particularly at high temperatures, and intervalley scattering is likely to have a significant effect on the thermoelectric figure of merit. Acoustic intervalley scattering is included in our calculations by following a method due to Herring [6]. An expression is obtained for the temperature dependence of the carrier mobility

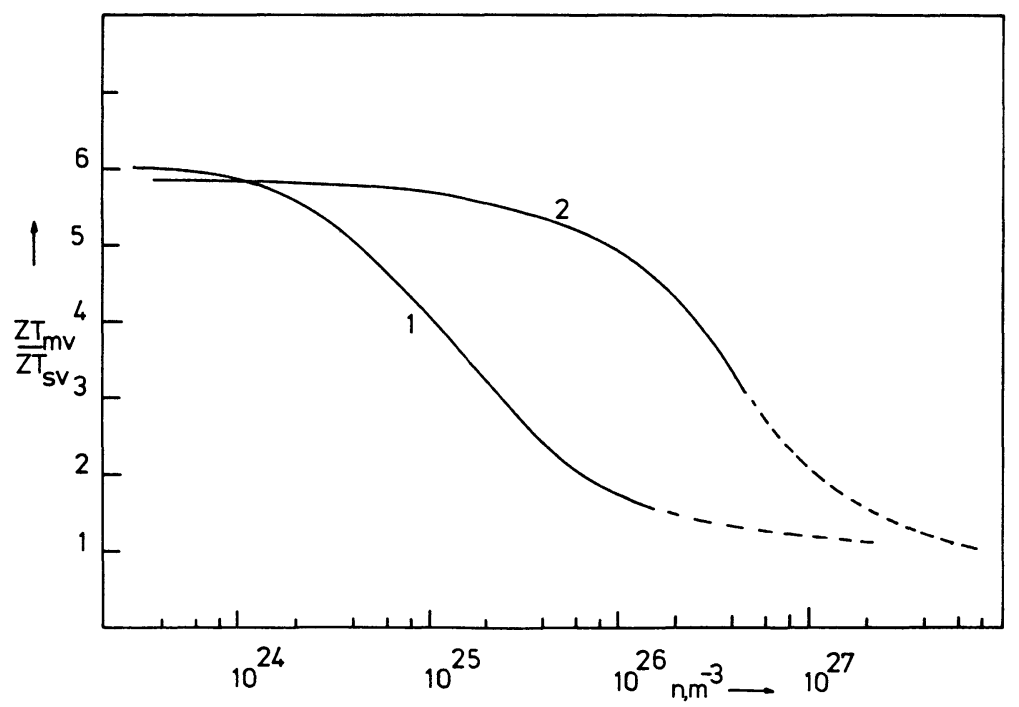

Fig. 1. - The ratio $(Z T)_{\mathrm{mv}} /(Z T)_{\mathrm{sv}}$ as a function of carrier concentration for $\mathrm{Si}_{70} \mathrm{Ge}_{30}$ alloy at $300 \mathrm{~K}$. Curve 1 : acoustic phonon scattering. Curve 2 : ionized impurity scattering. 


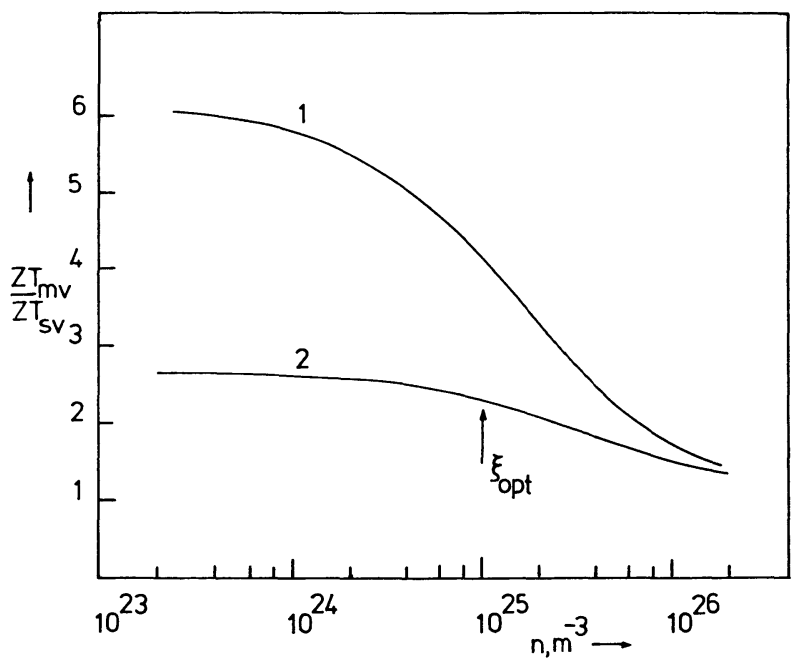

Fig. 2. - The ratio $(Z T)_{\text {mv }} /(Z T)_{\text {sv }}$ as a function of carrier concentration for $\mathrm{Si}_{70} \mathrm{Ge}_{30}$ alloy at $300 \mathrm{~K}$. Acoustic phonon scattering. Curve 1 : no intervalley scattering, $W_{2} / W_{1}=0$. Curve 2 : intervalley scattering included, $W_{2} / W_{1}=2.0$.

as a function of the ratio $W_{2} / W_{1}$, where $W_{2}$ and $W_{1}$ are measures of the strength of the carrier coupling to intervalley and intravalley acoustic modes respectively. The ratio $W_{2} / W_{1}$ is adjusted to give realistic values of the carrier mobility and the figure of merit. In figure 2 is displayed $(Z T)_{\mathrm{mv}} /(Z T)_{\mathrm{sv}}$ as a function of carrier concentration, assuming acoustic phonon scattering with (a) intravalley scattering, (b) intra and intervalley scattering.

The inclusion of intervalley scattering does not appreciably affect the ratio $(Z T)_{\mathrm{mv}} /(Z T)_{\mathrm{sv}}$ at low carrier concentrations. However, as is evident from the figure, its effect increases with increase in carrier concentration. It is concluded that intervalley scattering significantly reduces the beneficial effect of a multivalley energy band structure. At optimum doping level in silicongermanium alloys $\left(n \sim 10^{25} \mathrm{~m}^{-3}\right)$ intervalley scattering reduces the ratio $(Z T)_{\mathrm{mv}} /(Z T)_{\mathrm{sv}}$ by approximately $40 \%$.

\section{Acknowledgments.}

The United States Army, through its European Research Office, is acknowledged for sponsoring this research under contract No DAJA37-82-C-0116.

\section{References}

[1] Rowe, D. M., Bhandari, C. M., Modern Thermoelectrics (Holt, Rinehart and Winston, London) 1983.

[2] Goldsmid, H. J., Sheard, A. R. and Wright, D. A., B. J. Appl. Phys. 9 (1958) 365.

[3] URE, Jr., R. W. and HeIKes, R. R., Thermoelectricity; Science and Engineering, Eds. R. P. Heikes and R. W. Ure, Jr., (Interscience, New York) 1961.

[4] URE, Jr., R. W., Energy Conversion 12 (1972) 45.

[5] Bhandari, C. M. and Rowe, D. M., Proceedings of 5th International Conference on Thermoelectric Energy Conversion (Arlington, Texas) 1984, p. 38.

[6] Herring, C., Bell Systems Tech. J. 34 (1955) 237. 